\title{
RENDA BÁSICA DE CIDADANIA, DEFINIDA NA LEI N. 10.835/2004: DESAFIOS E OPORTUNIDADES PARA INCLUSÃO SOCIOECONÔMICA
}

\author{
Amanda Rutineia Cunha \\ Angélica Pereira Possamai \\ Yduan de Oliveira May
}

\section{INTRODUÇÃO}

O enfrentamento contra a pobreza no Brasil não é algo recente, esse tema vem sendo discutido durante anos e ganhou força expressiva com o projeto de lei que culminou na Lei n. 10.835, de 8 de janeiro de 2004, sancionada pelo então presidente Luiz Inácio Lula da Silva. Tendo o presente artigo como objetivo geral estudar a renda básica na perspectiva dos programas de garantia de renda mínima (PGRM), suas formas de aplicação no Brasil e no exterior, versando sobre os tipos de renda básica, trazendo exemplos de países onde existe a aplicação do PGRM, sobretudo, exemplos nacionais de recursos públicos destinados a essa função.

Sendo possível adiantar que os PGRM têm em comum, independente do país de origem, o mecanismo de combate à pobreza, permitindo aos seus beneficiários o mínimo de sobrevivência com o objetivo de suprir suas necessidades básicas. Nesse contexto, a principal motivação deste artigo é analisar os desafios e oportunidades atuais para a inclusão socioeconômica por meio da Lei n. 10.835 de 8 de janeiro de 2004 e a sua dificuldade de execução no atual quadro econômico. Além de apontar as principais críticas que esse tema segue enfrentando.

A fim de executar os objetivos propostos, adotou-se o método de abordagem dedutivo, o monográfico como método de procedimento, por meio da técnica de pesquisa em documentação indireta em pesquisa bibliográfica de fontes secundárias como doutrinas e legislações, com objetivo descritivo e explicativo (LAKATOS; MARCONI, 2001). 


\section{RENDA BÁSICA E A SOCIEDADE}

A renda básica é o complemento para as propostas de subsistência do Estado de Bem-Estar Social, devendo ser somada aos serviços públicos de saúde, educação através do ensino público, tendo como objetivo fornecer a cada indivíduo uma renda mínima necessária para sanar as necessidades básicas em prol da sua dignidade humana, operando como um mecanismo de combate à pobreza e à desigualdade social (INSTITUTO RECIVITAS, 2018).

Um sistema que concede incondicionalmente um benefício a todos os seus cidadãos, sem qualquer tipo de exclusão, está intimamente ligado ao princípio da igualdade, o qual implícita que todos os indivíduos são iguais e, portanto, devem receber os mesmos recursos provenientes do "dividendo social", caracterizando um novo modelo de intervenção estatal assentado no bem-estar coletivo, independentemente de pressupostos de condicionalidade, como aponta Opielka (2008, p. 4):

Nos últimos vinte e cinco anos tem se discutido sob diversas ópticas o trabalho e o emprego, alguns observadores apontam que com o desenvolvimento do mercado o desemprego se corrigirá por sí só, outros argumentam que a atual crise no mercado de trabalho é indicativo de uma mudança social mais profunda, abrindo espaço para a ideia de uma renda básica garantida a todos, baseada nos direitos humanos sem depender do mercado de trabalho. Desta forma, aponta o caminho para um novo contrato social baseado na ética e direitos humanos.

Diferentemente da renda mínima ou de outros programas de compensação, voltados a um determinado público-alvo que cumpre uma série de requisitos, a renda básica sustenta a ideia de um dever inalienável que proporciona para cada indivíduo o direito de equilibrar a sua vida em liberdade, propagando a sustentabilidade da sociedade. Esse novo tipo de contrato exige amadurecimento dos indivíduos para entender que a renda básica é um investimento de longo prazo, que substitui subsídios 
burocráticos, ineficazes e tradicionais, oferecendo a cada um o direito de priorizar o que é importante para si (OPIELKA, 2008). Acrescentando:

\begin{abstract}
A renda básica não se destina a encorajar as pessoas a se excluir da sociedade, mas sim capacitá-las a decidir por si próprias pelo que desejam optar. [...] A falta de discriminação, no entanto, irá seriamente melhorar a situação cultural e mental de todos aqueles que [...] procuram trabalho e acabam no desespero (embora sejam oferecidos trabalho social e serviços terapêuticos). Incentivo em vez de exclusão: isso seria ao mesmo tempo democrático e liberal. (OPIELKA, 2008, p. 6-7).
\end{abstract}

Contudo para que sua implementação seja eficaz é necessário haver o incentivo da grande maioria, evitando a discriminação. As principais subdivisões da renda básica estão expostas a seguir.

\title{
RENDA BÁSICA UNIVERSAL
}

A renda básica universal trata-se de uma renda incondicional paga a todos os indivíduos sem qualquer tipo de condição estabelecida, sem estar relacionada ao trabalho, caracterizada como um direito incondicional pago sistematicamente aos ricos e aos pobres. Promove a desburocratização, diminuindo a corrupção e privilégios, e aumentando a eficiência, pois não haveria custos com fiscalização, é viável se os recursos públicos forem utilizados em prol do interesse público. Como cita Van Parijs (1997) (apud DINIZ, 2007, p. 108), a renda básica universal atende muito embora atenda aos princípios de justiça distributiva, ela tem de enfrentar as seguintes problemáticas de aplicabilidade:

Que a adoção de uma renda básica universal atende a princípios igualitários parece não haver dúvidas. No entanto, uma questão importante é a de como atender a princípios de justiça em sociedades pobres? Embora Van Parijs (1994) seja um fervoroso defensor da renda básica universal incondicional, ele não recomenda a introdução de uma renda básica a todas sociedades. 
Para ele, somente em sociedades que se livraram da fome, ou que podem fazê-lo sem violação à propriedade de si mesmo, é que vale a pena falar em renda básica. Há pelo menos dois problemas a serem enfrentados no que diz respeito à adoção de uma renda básica universal em sociedades pobres: número excessivo de beneficiários e poucos recursos a serem distribuídos.

Existem inúmeras preocupações sobre os impactos desse modelo de renda básica, principalmente, por não estar vinculada a qualquer tipo de condição, dessa forma, o número de beneficiários seria o número de pessoas do país de aplicação, o que poderia iniciar uma crise econômica. Outro ponto alvo de críticas é que desestimularia os indivíduos a trabalhar, além de ser injusto pensar que "aqueles que não precisam" os ricos, também seriam beneficiados.

Noentanto, temosquelevarem consideração, primeiramente, que a aplicação desse tipo de modelo é algo relativamente novo, ora, os países que forem aderir à renda básica universal farão as devidas modificações no projeto para que se encaixe com as suas condições econômico-financeiras para fins de concessão aos seus cidadãos, a qual poderia ser aumentada sucessivamente na medida em que a disponibilidade de recursos também fosse maior. Quanto à desestimulação ao trabalho, acrescenta Bregman (2017), em seu estudo sobre o capitalismo:

A renda básica seria fundamental, pois permitiria pela primeira vez na história que as pessoas pudessem recusar trabalhos que não quisessem realmente fazer. Hoje em dia esse é um privilégio ao alcance apenas dos mais ricos, mas, caso se implementasse a renda básica, seria um direito de todos. Hoje se diz às crianças que elas precisam estudar para alguma profissão que lhes dê dinheiro. Com a renda básica, elas poderiam fazer o que bem entendessem na vida.

Bregman complementa que "[...] as pesquisas mostram que todos nós queremos realizar os nossos sonhos. E o grande desperdício dos nossos dias são os milhões de pessoas que estão presas à pobreza ou a um 
trabalho inútil." (BREGMAN, 2017), logo, a renda básica proporcionaria o desenvolvimento de atividades laborais realmente úteis, maximizando as oportunidades de crescimento aos países que aderirem este modelo.

\section{RENDA BÁSICA GARANTIDA}

A renda básica garantida propõe o mesmo que a renda universal, além de assegurar a continuidade do seu pagamento e garantir o recebimento a todos os cidadãos do território nacional, sejam natos ou naturalizados, tornando-se, portanto, uma garantia social.

É o que pretende o Projeto de Lei do Programa de Garantia de Renda Mínima no Brasil, apresentado ao Senado brasileiro em 1991 e concretizado na Lei de n. 10.835 de 2004, que dispõe em seu artigo 1ㅇ: "É instituída, a partir de 2005, a renda básica de cidadania, que se constituirá no direito de todos os brasileiros residentes no País e estrangeiros residentes há pelo menos 5 (cinco) anos no Brasil, não importando sua condição socioeconômica, receberem, anualmente, um benefício monetário". (BRASIL, 2004).

Consiste em um valor igualitário para todos os beneficiários, ricos e pobres, sem distinções, sendo garantido conforme estipula o parágrafo 2 o do artigo 10 , “O pagamento do benefício deverá ser de igual valor para todos, e suficiente para atender às despesas mínimas de cada pessoa com alimentação, educação e saúde, considerando para isso o grau de desenvolvimento do País e as possibilidades orçamentárias." (BRASIL, 2004), como explica Diniz (2007, p. 111):

A lei que cria uma renda básica de cidadania (RBC) consiste no direito de todos os brasileiros residentes no país, além de estrangeiros que vivem há pelo menos cinco anos no Brasil, a uma renda mínima, não importando a sua condição socioeconômica. O pagamento do benefício deverá ser de igual valor para todos e suficiente para atender às despesas mínimas de cada pessoa com alimentação, educação e saúde, considerando para isso o grau de desenvolvimento do país e as suas possibilidades orçamentárias. O 
pagamento do benefício poderá ser feito em parcelas iguais e mensais. Trata-se ainda de benefício não tributável para efeito do imposto de renda.

Sendo assim, assegura o pagamento de uma renda básica incondicional a todos os brasileiros, atendendo aos preceitos de uma sociedade mais justa. A referida lei assegura em seu parágrafo 10 , artigo 10 , que concessão do pagamento do benefício será voltada, inicialmente, as camadas carentes da população, nos seguintes termos: "A abrangência mencionada no caput deste artigo deverá ser alcançada em etapas, a critério do Poder Executivo, priorizando-se as camadas mais necessitadas da população." (BRASIL, 2004).

No entanto, não está disposto o valor inicial do pagamento, apenas que este será definido pelo Poder Executivo de acordo com as possibilidades orçamentárias do país, conforme restou determinado no artigo 20 "Caberá ao Poder Executivo definir o valor do benefício, em estrita observância ao disposto nos arts. 16 e 17 da Lei Complementar n. 101, de 4 de maio de 2000 - Lei de Responsabilidade Fiscal." (BRASIL, 2004).

Para a execução deste programa os recursos seriam pagos pela União e pretendia-se desativar outros programas de política social compensatória, concentrando toda a alocação de recursos disponíveis para este programa (DINIZ, 2007).

Para cumprir com objetivo geral de combate à pobreza e à desigualdade social é necessário que o valor destinado a cada indivíduo deve suprir as suas despesas mínimas, esta que está atrelada ao "mínimo existencial", intimamente ligado com o direito universal da dignidade da pessoa humana (WEBER, 2013).

Segundo Weber (2013, p. 198), o mínimo existencial “[...] referese à preservação e garantia das condições e exigências mínimas de uma vida digna. Isso significa dizer que o direito ao mínimo existencial está alicerçado no direito à vida e na dignidade da pessoa humana.", sendo que, deve ser protegido e promovido pelo Estado, complementando: 
Os direitos fundamentais, sobretudo os sociais, são, nesse caso, a expressão do conteúdo da dignidade humana e a sua realização efetiva nas instituições sociais. É, portanto, a partir da dignidade, como fundamento constitucional, que se justifica e até mesmo se impõe o reconhecimento do direito ao mínimo existencial. [...] A definição do conteúdo desse mínimo existencial é, no entanto, objeto de muita divergência. Entendê-lo como a satisfação das necessidades básicas da vida uma espécie de sobrevivência física - é restrito demais. Sarlet, referindo-se à efetivação da dignidade da pessoa humana, chama a atenção para o mínimo existencial como um direito fundamental, que diz respeito não só a "um conjunto de prestações suficientes apenas para assegurar a existência (a garantia da vida) humana, [...] mas uma vida com dignidade, no sentido de vida saudável". Coloca, portanto, em sua base, a dignidade e suas formas de concretização e não reduz o mínimo existencial ao "mínimo vital". (WEBER, 2013, p. 199).

Portanto, o mínimo existencial não engloba somente prestações materiais para a garantia da sobrevivência, mas, também, o desenvolvimento de tudo o que for necessário à vida. $\mathrm{O}$ apelo à dignidade tem se mostrado recorrente nas decisões de diversos tribunais sobre diferentes matérias:

[...] ignorar a existência e a validade jurídica das uniões homoafetivas é o mesmo que as pôr em situação de injustificada desvantagem em relação às uniões estáveis heterossexuais. Compete ao Estado assegurar que a lei conceda a todos a igualdade de oportunidades, de modo que cada um possa conduzir sua vida autonomamente segundo seus próprios desígnios e que a orientação sexual não constitua óbice à persecução dos objetivos pessoais. [...] Essa ordem de ideias remete à questão da autonomia privada dos indivíduos, concebida, em uma perspectiva kantiana, como o centro da dignidade da pessoa humana. [...] [a] previsão de que o indivíduo mereça do Estado e dos particulares o tratamento de sujeito e não de objeto de direito, respeitando-se-Ihe a autonomia, pela sua simples condição de ser humano. (FRIAS; LOPES, 2015 apud STF, 2011, grifo nosso). 
[...] As violações ambientais mais graves recentemente testemunhadas no plano internacional e no Brasil, repercutem de modo devastador na esfera dos direitos humanos e fundamentais de comunidades inteiras. $E$ as graves infrações ambientais podem constituir, a um só tempo, graves violações de direitos humanos, máxime se considerarmos que o núcleo material elementar da dignidade humana "é composto do mínimo existencial, locução que identifica o conjunto de bens e utilidades básicas para a subsistência física e indispensável ao desfrute da própria liberdade. Aquém daquele patamar, ainda quando haja sobrevivência, não há dignidade". (FRIAS; LOPES, 2015 apud STF, 2017).

As ações e serviços na área de saúde têm por diretriz o atendimento integral do indivíduo, o que consiste no fornecimento de medicamentos necessários à preservação da vida, ainda que não sejam padronizados pelo SUS. Conforme relatório médico subscrito por profissional inscrito no Conselho Regional de Medicina, não há no país insumo semelhante ou genérico, o que corrobora a imprescindibilidade do suplemento. Os princípios informadores da administração pública e a cláusula da reserva do possível não se aplicam quando se está diante de direitos fundamentais, em que se busca preservar a dignidade da vida humana. (FRIAS; LOPES, 2015 apud STF, 2017, grifo nosso).

Portanto, é a partir da dignidade da pessoa humana que se justifica a necessidade de ser assegurado o mínimo existencial aos indivíduos, contexto que justifica a implementação do PGRM, garantindo a qualidade de vida e dando margem de escolha aos indivíduos, garantindo a liberdade. Com base nisso, surge a construção de uma sociedade mais justa e capaz de implementar a justiça distributiva, a partir da garantia da igualdade socioeconômica, com ações e diretrizes que proíbem a insuficiência dos direitos fundamentais básicos, permitindo que cada cidadão possa gozar de seus direitos por meio de programas socioeconômicos, como este da renda básica. 


\section{PROGRAMA DE GARANTIA DE RENDA MÍNIMA NOS PAÍSES DESENVOLVIDOS}

Os países desenvolvidos também aderiram ao programa de garantia de renda mínima como forma de compensação, complemento de renda e meio para proporcionar uma melhor qualidade de vida aos seus cidadãos. Sendo que

[...] a implantação de programas dessa natureza não é recente. Na Europa Ocidental, na Dinamarca, o programa foi implantado em 1933, na Inglaterra em 1948, na Alemanha em 1961, na Holanda em 1963, na Bélgica em 1974, na Irlanda em 1977, em Luxemburgo em 1986 e na França em 1988. (LAVINAS; VARSANO, 1998 apud DINIZ, 2007, p. 106).

Há um núcleo comum nos programas desses países:

a) destinam-se a todos aqueles que se encontram em situação de necessidade decorrente de insuficiência de renda - respeitam, portanto, um princípio de universalidade; b) o benefício é atribuído com base em uma demanda feita pelo próprio interessado; c) implicam no respeito a certas prerrogativas e, em alguns casos, a contrapartidas; d) o benefício tem seu valor modulado pelo montante das demais prestações sociais e pela renda individual ou familiar do requerente. (DINIZ, 2007, p. 106).

A aplicação dessas formas de PGRM possui requisitos para a sua concessão ligados ao número de filhos, à idade dos filhos e ao nível de rendimentos, como mencionam Suplicy e Cury (1994, p. 103):

Os países desenvolvidos atualmente possuem diversas formas de PGRM, a exemplo, na Inglaterra, Alemanha e Holanda, os pais das crianças de até 16 anos recebem um benefício mensal, que na Alemanha é de 50 marcos, na Inglaterra é de 9,65 libras (semanais) para crianças 
que forem mais velhas, e de 7,80 libras para das demais, este benefício é pago até os 19 anos, se a criança estiver estudando. Na França todos os seus cidadãos, cuja renda for inferior a 2.184,79 francos, e de idade igual ou superior a 25 anos, recebem a "Renda Mínima de Inserção" até aquele valor máximo, por três meses, podendo ser ampliado por até 12 meses. Nos Estados Unidos, está implantada, desde 1975, uma forma de imposto de renda negativo chamada Earned Income TaxCredit (EITC), para famílias com renda inferior a US\$ 23.760 e que possuam pelo menos um filho vivendo com elas, os que possuem dois ou mais filhos, recebem um crédito que equivale a $25 \%$ de US\$ 7.990 , o que resulta num crédito de US\$ 1.998 anuais, permanecendo neste nível até que os rendimentos ultrapassem US\$12.570, sendo diminuído gradativamente até que atinjam US\$ 23.760 .

Se os países desenvolvidos atenderam à discussão sobre uma renda mínima, sendo que possuem uma realidade muito diferente da brasileira, podemos imaginar o quanto um PGRM mais focalizado e com maiores recursos podem atender ao déficit socioeconômico no Brasil.

\section{PROGRAMA DE GARANTIA DE RENDA MÍNIMA NO BRASIL}

Suplicy e Cury (1994) afirmam que a ideia de um complemento para renda surgiu no século XVI com a Lei dos Pobres, primeiramente, por meio das paróquias e, mais tarde, como responsabilidade da nação, ao contrário do que citam nos livros, essa lei na sua forma de vigor (antes da emenda de 1834) não reduzia a eficiência dos trabalhadores agrícolas, não estimulava o crescimento da população ou destruía pequenos proprietários rurais, ao contrário, era um instrumento para lidar com as questões do desemprego e dos baixos salários no setor rural ainda subdesenvolvido, contribuindo para uma forma de "estado de bem-estar" e expansão econômica. 
Expondo que o país padece sobre o fenômeno da exclusão social, o deputado Paulo Bernardo, em seu voto no projeto da referida lei objeto deste artigo, exemplifica que:

\begin{abstract}
Em nosso País, assim como em outros, a pobreza é histórica e estrutural. Ela é resultado de uma longa trajetória de exclusão social de segmentos populacionais determinados. Para a sua configuração, fatores como a indigência econômica, a falta de acesso a serviços sociais básicos - como educação e saúde -, o desconhecimento de princípios básicos de cidadania, a desestruturação familiar e pessoal associam-se e reforçam-se mutuamente. O fenômeno da exclusão social no Brasil, onde sequer conformou-se um Estado de Bem-Estar Social nos moldes dos países desenvolvidos, além de significar falta de cidadania, é fortemente agravado pela alta concentração de renda e de riquezas, como já assinalamos. (CÂMARA DOS DEPUTADOS, 2003, p. 12).
\end{abstract}

Explicando ainda que:

Em um artigo publicado em 2001 pelo Instituto de Pesquisa Econômica Aplicada, Barros, Henriques e Mendonça concluem que, no Brasil atual, a pobreza é mais sensível à desigualdade do que ao crescimento econômico. Segundo eles, malgrado seja o crescimento da economia uma importante via de enfrentamento da pobreza, ela é lenta. Para cada $3 \%$ de incremento anual da renda per capita, os níveis de pobreza demoram dois anos para decrescerem em apenas $1 \%$. De acordo com os autores, se fosse alterado o perfil de desigualdade brasileiro para um padrão condizente com nosso desenvolvimento econômico, haveria uma redução da ordem de $36 \%$ na pobreza brasileira, ainda que inexistisse crescimento da economia. (CÂMARA DOS DEPUTADOS, 2003, p. 9-10).

No Brasil, o combate à pobreza não é um debate recente, visto que está entre os principais países com o maior número de 
desigualdades de distribuição de renda, que sempre existiu na história do País, e, eclodiu com o Milagre Brasileiro, que proporcionou crescimento econômico concentrado no polo das camadas mais ricas da sociedade e a pauperização do polo oposto, visto que, a legislação pouco explorava questões de política social, como Draibe (1989 apud DINIZ, 2007, p. 108) vem a aludir:

Entre os anos 1930 e 1940, a legislação social tratava, quase que exclusivamente, de questões previdenciárias e trabalhistas, e tinha como objetivo, embora nem sempre tenha sido alcançado, assegurar proteção aos trabalhadores urbanos, tendo em vista os baixos valores das aposentadorias e pensões. As outras áreas englobadas sob o rótulo de política social (educação, saúde, assistência social e, por último, habitação) tomaram formas mais institucionalizadas entre $1945 \mathrm{e}$ 1964.

Draibe (1989 apud DINIZ, 2007, p. 108) menciona que "[...] o processo constituinte de 1988 acenou com a possibilidade de um novo modelo de política que privilegiasse medidas de justiça social. Durante o período da 'Nova República' cresceu o número de programas assistenciais sem base contributiva [...]", e complementa que "[...] esboçaram-se os primeiros passos em caminho à descentralização, principalmente na área da saúde, e começava a tomar corpo o debate quanto à necessidade de garantir a todos os cidadãos uma renda mínima". Sendo que a adoção de uma política de renda mínima no Brasil é justificada a partir de três argumentações.

A adoção de uma política de renda mínima no Brasil, de acordo com Ramos (1998), vem sendo justificada a partir de três argumentações. A primeira delas é que um programa desta natureza romperia com a prática amplamente disseminada na política brasileira, de intermediação, pelos políticos profissionais, dos benefícios sociais de caráter estatal. Um dos desdobramentos de uma renda mínima garantida seria uma contribuição às mudanças nas práticas políticas e 
à democracia, na medida em que a utilização pessoal ou partidária de recursos públicos deixaria de ser uma ferramenta de campanha eleitoral. Em segundo lugar, as pessoas que estão fora do mercado formal de trabalho passariam a ter acesso a, pelo menos, um benefício mínimo. Por fim, a renda mínima poderia se tornar um instrumento de distribuição de renda: (RAMOS, 1998 apud DINIZ, 2007, p. 109).

$\mathrm{Na}$ atualidade, muitos países desenvolvidos introduziram o PGRM, como forma de combate à pobreza, no Brasil, essa ideia foi apresentada em 1991 com o projeto de lei do então senador Eduardo Suplicy, por meio da forma de Imposto de Renda Negativo.

No Brasil, em 1991, foi apresentado ao senado brasileiro um projeto de lei criando o PGRM, no qual todos os residentes no Brasil com idade igual ou superior a 25 anos, com a renda mensal inferior a $\mathrm{Cr} \$ 45.000,00$ (cruzeiros) em torno de US\$140, possuem direito a um imposto de renda negativo de $30 \%$ da diferença entre essa quantia e sua renda. Ficando vinculado à disponibilidade de recursos do poder Executivo. [...] Para que o PGRM possa operar no Brasil, deverá ser financiado com recursos federais, sendo cortados os programas que não sejam eficientes, os indivíduos que possuam rendimento acima de certo patamar terão que pagar imposto de renda variando de $15 \%$ a $25 \%$ de seus rendimentos. $O$ benefício será concedido para as pessoas com idade igual ou superior a 60 anos, no primeiro ano, em seguida contemplará àqueles com idade igual ou superior a 55 anos e assim sucessivamente, até que no oitavo ano, todos os cidadãos com mais de 25 anos de idade terão direito ao PGRM. Se for viável este programa pode ser implementado em toda a sua totalidade e o índice de 30\% poderá ser aumentado. (SUPLICY; CURY, 1994, p. 103-104).

Ao longo dos anos, diversos programas de renda mínima foram implementados no Brasil, visando a diminuir os abismos sociais e 
econômicos, sendo que estes possuíam requisitos para a sua concessão, como a permanência das crianças na escola, dos quais se destacam:

Em janeiro de 2004, o presidente Lula sancionou o seu principal programa social - o Bolsa Família (PBF), criado pela Lei n. 10.836/04, a partir de uma medida provisória editada pelo Executivo. Essa lei unificou o Bolsa Escola (Lei n. 10.219, abril de 2001), o Programa Nacional de Acesso à Alimentação (Lei n. 10.689, de junho de 2003), o Bolsa Alimentação (Medida Provisória n. 2.206-1, de setembro de 2001), o Auxílio-Gás (Decreto 4.102, de janeiro de 2002) e o Cadastramento Único do Governo Federal (Decreto n. 3.877, julho de 2001). No mesmo ano de sanção do PBF, 2004, a Presidência da República também sancionou o projeto de lei do senador Suplicy, Lei 10.835/04 que dispõe sobre o Programa Renda Básica de Cidadania. (DINIZ, 2007, p. 111).

Desde que a Lei n. 10.835/2004 foi sancionada ainda não houve a sua devida aplicação em nível federal, nem mesmo da primeira etapa do projeto. O Orçamento Geral da União de 2005 até o ano de 2018 não promoveu nenhum tipo de diretriz especificando as despesas necessárias para a execução da referida lei, muito embora se acredite que tal programa será mais eficiente no combate à pobreza e à desigualdade social, pois teria um alcance muito mais satisfatório na distribuição do benefício. Porém, o PGRM irá ser apresentado para aplicação no estado de São Paulo.

\section{PROGRAMA DE RENDA MÍNIMA NO MUNICÍPIO DE SÃO PAULO}

Na prática brasileira o PGRM exige o cumprimento de requisitos para a sua concessão, sendo transferido a famílias de baixa renda que possuam dependentes menores de 14 ou de 16 anos, ou seja, recebem tal benefício a instituição familiar, com filhos dependentes com faixa etária escolar. Argumentando Pochmann (2002, p. 86) que o programa atinge tais objetivos: 
Ao longo desses anos (1995-2001) a experiência brasileira tem sido marcada por condicionar o repasse de recursos às famílias pobres e ao ingresso e à permanência de suas crianças na rede escolar. Oferecer meios para que as famílias possam dispensar a contribuição de suas crianças e adolescentes à renda familiar e comprometêlas com a frequência escolar de seus filhos tem sido a tônica dos programas. Vale dizer que esse é o núcleo dos programas, eles ainda têm como objetivos: erradicar o trabalho infantil, retirar as crianças das situações de vulnerabilidade a que estão submetidas nas ruas das cidades, combater a desnutrição infantil, entre outros.

Pochmann (2002, p. 87) menciona que iniciativas municipais e estaduais associaram-se ao PGRM associado a Ações Socioeducativas, estabelecido pela Lei n. 9.533/97, sendo que a referida lei autorizou ao Poder executivo disponibilizar apoio financeiro aos municípios que aderissem ao PGRM agregado a ações socioeducativas, sendo entendida "[...] como a possibilidade de uma intervenção um pouco mais equalizadora da desigual capacidade dos municípios para implantarem programas de distribuição de benefício monetários." Explicando que a Lei n. 12.651, de 6 de maio de 1998, regulamentada pelo Decreto n. 40.400, de 5 de abril de 2001, indica que estão aptas para aderir ao Programa de Garantia de Renda Familiar Mínima Municipal as famílias que atendam às seguintes condições (POCHMANN, 2002, p. 88):

[...] tenham crianças e adolescentes entre 0 e 14 anos; (2) residam em São Paulo há, no mínimo, dois anos; (3) aufiram renda bruta mensal inferior a três salários mínimos; (4) atendam às obrigações estabelecidas em Termo de Responsabilidade e Compromisso. [...] Para serem beneficiadas e seguirem como tal, a legislação do programa ainda estabelece como condições a serem observadas pelas famílias a assiduidade à escola para as crianças e os adolescentes e a retirada destes das situações de risco (trabalho nas ruas, por exemplo).

Concluindo que, o PGRM além de ser um meio de distribuição de renda, também, possui como objetivo assegurar a formação intelectual 
de crianças e de adolescentes, não apenas distribuindo renda, mas buscando amenizar o ciclo de reprodução de pobreza, para que as crianças tenham igualdade de oportunidades para o alcance de uma vida digna, visando ainda, em curto prazo, à redução de crianças e adolescentes nas ruas já inseridas em atividades ilícitas ou em situações de risco, proposta que, então, além de melhorar a qualidade de vida das famílias brasileiras erradicando a pobreza, garante a igualdade de oportunidades a fim de reduzir as desigualdades socioeconômicas, assegurando o desenvolvimento pleno nacional.

\section{PROGRAMA DE RENDA MÍNIMA NA ALDEIA MORRO DA SAUDADE EM SÃO PAULO}

Nos anos de 2003 e 2004, foi instituído o programa de renda mínima na Aldeia Indígena Morro da Saudade em São Paulo, pela Prefeitura do Município de São Paulo (SP), no intuito de promover a inclusão socioeconômica dessa comunidade que vive em situação de vulnerabilidade.

Uma vez que, como menciona Fabbri e Ribeiro (2007, p. 62-63), as "[...] influências e pressões produzem um efeito desagregador sobre a cultura, a organização social e a economia destes grupos, tornandoos vítimas da exclusão social e da carência de recursos [...]", tornando o PGRFM (Programa de Renda Familiar Mínima) uma forma de melhora na condição de vida dessa comunidade. Explicando as peculiaridades desse programa, uma vez que a inserção de tal programa em aldeia indígena envolve problemáticas antropológicas:

Para a inclusão da comunidade indígena nos programas sociais foi necessária a contratação de uma assessoria antropológica para conciliar o direito ao acesso a programas oficiais municipais com o direito constitucional dos índios de terem seus costumes e tradições respeitadas. Da análise realizada pela assessoria, em conjunto com a comunidade indígena, concluiu-se que, dos programas sociais de transferência de renda, o Programa de Garantia de Renda Familiar 
Mínima (PGRFM) era o que mais atendia às expectativas dessas comunidades. (FABBRI; RIBEIRO, 2007, p. 62-63).

Para a aplicação do PGRFM foram utilizados requisitos de concessão como o número de filhos, se frequentavam ou não a escola e o tempo de moradia na aldeia, contextualizando a realidade da implementação de tal programa:

As lideranças identificaram as famílias que não preenchiam os requisitos contidos na legislação do programa (famílias sem filhos, ou filhos acima de 15 anos de idade ou fora da escola), e outras que não deveriam ingressar no programa pelo fato de não morarem na aldeia por mais de dois anos. O total de famílias na aldeia Morro da Saudade anterior ao cadastramento, registrado em relatório antropológico no ano de 2003, informava a existência na aldeia de 130 famílias. Desse total, 89 foram cadastradas e outras 41 não o foram por não terem comparecido. Uma das razões pode ter sido o fato de não preencherem algum critério, não terem filhos na faixa de idade exigida, ou os filhos não estarem estudando, ou ainda estarem em deslocamento para outras aldeias, ou alguma outra situação. (FABBRI; RIBEIRO, 2007, p. 65).

Era imprescindível respeitar os padrões culturais da aldeia e designar um teto mínimo de renda familiar. Com implementação do programa houve um aumento superior ao dobro na renda das famílias indígenas, como esclarece Fabbri e Ribeiro (2007, p. 68-69):

A introdução do PGRFM na aldeia Morro da Saudade trouxe um significativo e abrupto aumento da renda das famílias indígenas. Tomando como parâmetro as rendas pré-existentes (declaradas no cadastramento), no valor médio de $\mathrm{R} \$ 5.931,00$ por mês para a totalidade das 67 famílias, podemos concluir que houve um aumento superior ao dobro para o total da renda das famílias selecionadas, e também para a renda per capita dos seus integrantes. Isso significa que a circulação de receitas 
de posse das famílias integrantes do PGRFM aumentou substancialmente e que a circulação de bens na aldeia também aumentou. Significa, também, em termos qualitativos, que o PGRFM provavelmente introduziu algumas diferenças sociais importantes ao nível da renda das pessoas, o que, na ausência de uma política intersetorial para o conjunto da população da aldeia, pode ter contribuído para colocar em questão tanto as relações igualitárias entre seus membros como a própria relação das famílias com as lideranças indígenas. [...] Os objetivos do programa renda mínima se concentram na melhoria das condições atuais de vida do seu público-alvo preferencial, as crianças e os adolescentes. Para atender esses objetivos realiza-se uma transferência monetária às respectivas famílias, com o compromisso de estas assegurarem a permanência e um bom desempenho das crianças e dos adolescentes na rede pública de ensino, contribuindo com o aumento dos anos de escolaridade.

Verificando que os principais meios de subsistência da aldeia são os pequenos cultivos, artesanato e doações, o PGRFM impulsiona uma grande melhora na qualidade de vida do grupo, porém ainda falha na sua concessão por haver requisitos e condições, propaga a injustiça para àqueles que não se adequam a concessão do benefício. Dessa forma, concluíram que:

[...] seria importante dizer que o Programa de Garantia de Renda Familiar Mínima voltado para a sociedade indígena condiciona a transferência de renda às famílias mais pobres da aldeia a certas exigências, obrigando os beneficiários a se submeterem a averiguações de toda a sorte. Esse processo pode ser visto sob duas óticas: a primeira é a da busca de equidade, por meio da qual critérios de justiça e de objetividade são plasmados, tornando possível ajustar o benefício a determinadas normas e instituições sociais que fazem parte da sociedade envolvente e são comumente aceitas por ela; a segunda é a burocratização da concessão do benefício, por meio da constituição de um aparelho, operando dispositivos e controles, para referendar a aplicação concreta da referida lei. Nesse caso, há indiretamente o 
risco de cometer e propagar injustiças, as quais ficarão perdidas nos desvãos da Lei. (FABBRI; RIBEIRO, 2007, p. 70).

Diferentemente seria se houvesse a aplicação da Lei de Renda Básica de Cidadania, Lei 10.835/2004, que prevê a desburocratização e pretende eliminar requisitos para a sua concessão, estando, portanto, ao alcance de todos. Explicando que o cenário se encontrava da seguinte forma:

Em 2007, o programa continua com as mesmas características e o número de beneficiários teve em pequeno aumento. Diferente seria o caso da aplicação, nas aldeias indígenas, da Lei de Renda Básica de Cidadania de autoria de Suplicy (2002) que prevê uma renda básica incondicional, que será de igual valor para cada cidadão brasileiro ou estrangeiro residente há pelo menos cinco anos no Brasil, pagável mensalmente, e suficiente para cobrir as despesas mínimas com alimentação, habitação, educação e saúde, levando em consideração o grau de desenvolvimento do país e suas possibilidades orçamentárias. (FABBRI; RIBEIRO, 2007, p. 74-75).

Desta forma, a aplicação do programa nos termos da Lei de Renda Básica de Cidadania, ao invés da maneira como foi introduzido na Aldeia Morro da Saudade em São Paulo proporcionaria um maior número de beneficiários, devido à desburocratização do programa, atingindo de maneira mais abrangente os objetivos gerais almejados, quais sejam, combate à pobreza e à desigualdade social, no entanto é importante mencionar que para tanto há exigência da existência de orçamento público.

\section{CONSIDERAÇÕES FINAIS}

A partir da pesquisa desenvolvida sobre a renda básica foi possível observar que a Lei n. 10.835/2004 - que constituiu a renda 
básica em todo o território nacional como direito de todos os cidadãos residentes no País e estrangeiros residentes há pelo menos 5 anos - não está sendo devidamente implementada no Brasil por motivos orçamentários, ineficiência estatal, não se tornando-se uma política pública, inexistindo ação governamental para assegurar e promover a lei sancionada, apesar de ser pautada no melhor interesse do ser humano, qual seja, a erradicação da pobreza, da marginalização e da redução das desigualdades entre as classes.

Sobretudo, destaca-se que a renda básica pode vir a cumprir com a norma programática constitucional prevista no artigo 3ำ, a qual determina como objetivo da República Federativa Brasileira a construção de uma sociedade livre, justa e solidária, a diminuição da pobreza e das desigualdades sociais e regionais. No entanto, o que ficou evidente é que até o presente momento foram implementados somente programas burocráticos, os quais não atingem o objetivo de forma abrangente e eficiente, acabando por refletir ainda mais o problemático quadro políticoeconômico brasileiro ineficiente, bagunçado, vergonhoso, que sofre com os recorrentes escândalos de corrupção com o desvio de verbas públicas.

Também se verificou que não há espaço na mídia para a divulgação desse direito social, visto que esse assunto nunca foi divulgado, fazendo com que a grande parte da população desconheça tal direito garantido por lei. Sendo importante afirmar que o Brasil é um país rico, ou seja, possui riquezas a serem distribuídas, no entanto, é um país extremamente desigual, com um governo desorganizado e corrupto. A pobreza e a desigualdade social devem ser combatidas, pois dão imperativos de uma social-democracia, em prol da justiça distributiva, porém, tais fatores são obstáculos para a concretude de tal direito.

Muito embora existam programas com caráter de distribuição de renda, estes foram implementados em nível local não federal, sendo políticas públicas que não alcançaram os resultados desejados, sendo a desigualdade social no Brasil ainda latente, conforme estatísticas sociais publicadas em 29 de novembro de 2017 pelo Instituto Brasileiro de Geografia e Estatística (IBGE), com última atualização em 1으 de dezembro de 2017, sob o uso do coeficiente de Gini, que varia de zero (perfeita igualdade) até um (desigualdade máxima), estando o Brasil com índice 
de 0,549, índice altíssimo, que expressa a triste realidade brasileira com relação à desigualdade social (IBGE, 2017).

Todavia, o ordenamento jurídico brasileiro já traz alternativas socioeconômicas para tal fim, como é o caso da Lei n. 10.835, de 8 de janeiro de 2004 que institui a renda básica de cidadania.

Sendo assim, tem-se um cenário em que o País tem elevado número de pobreza e políticas públicas ineficientes, as quais excluem um grande número de pessoas devido aos requisitos que burocratizam os programas, mesmo frente à necessidade de realmente desafiar e melhorar o histórico de injustiça social que marginaliza grande parte da população, que faz com que não tenham acesso a condições mínimas igualdade de oportunidades. Há indícios de que os PGRM afetam positivamente as famílias beneficiadas, no entanto, a viabilização de recursos para esses programas precisa ser ainda mais abrangente e o programa em si precisa ser mais focalizado.

Conclui-se, portanto, que a renda básica seria uma forma mais eficaz de combateàs desigualdades do que os programas jáimplementados, pois é concebida de maneira universal a todos os cidadãos, o que otimiza o acesso dos beneficiários aos recursos, além de dar liberdade as pessoas na escolha do seu trabalho, diminuir custos com fiscalização, assegurar o mínimo existencial, proporcionar expansão econômica, melhorar a vida daqueles que se encontram em situações de risco e também melhorar a qualidade de vida de todas as famílias.

Tamanha a importância, portanto, da implementação desse programa nos moldes previstos na referida lei, no entanto, ainda que a Constituição Federal brasileira seja pautada na garantia de igualdade entre os indivíduos, os interesses privados continuam a se sobressair sobre os interesses públicos, o que gera a má distribuição de renda, aumentando o abismo entre as classes sociais brasileiras, e, por fim, limita a distribuição de recursos para projetos que realmente beneficiem o corpo de cidadãos brasileiros, o que faz com que a execução da lei continue em processo de regularização há 13 anos. 


\section{REFERÊNCIAS}

BRASIL. Lei n. 10.835, de 8 de janeiro de 2004. Institui a renda básica de cidadania e dá outras providências. Brasília, DF, 2004. Disponível em: http://www.planalto.gov.br/ccivil_03/_ato2004-2006/2004/lei/l10.835.htm. Acesso em: 1익. 2018.

BREGMAN, R. A renda básica universal seria a maior conquista do capitalismo. El País, 2017. Disponível em: https://brasil.elpais.com/brasil/2017/03/23/economia/1490287072_800265.html. Acesso em: 1o set. 2018.

CÂMARA DOS DEPUTADOS. Projeto de Lei n. 254-A de 2003. Institui a renda básica de cidadania e dá outras providências. 2003. Disponível em: http:// www.camara.gov.br/proposicoesWeb/prop_mostrarintegra;jsessionid=865D0732COBC915B72E884E06955A172.node1?codteor=231876\&filename=Avulso+-PL+254/2003.

Acesso em: 11 mar. 2018.

DINIZ, S. Critérios de justiça e programas de renda mínima. Katál, Florianópolis, v. 10, n. 1, p. 105-114, jan./jun. 2007.

FABBRI, E.; RIBEIRO, H. Programa Renda Mínima na Aldeia Indígena Morro da Saudade em São Paulo entre 2003 e 2004: análise de uma experiência. Saúde e Sociedade, São Paulo, v. 16, n. 2, p. 61-75, 2007.

FRIAS, L.; LOPES, N. Considerações sobre o conceito de dignidade humana. Revista Direito GV, São Paulo, v. 11, n. 2, p. 649-670, jul./dez. 2015.

INSTITUTO BRASILEIRO DE GEOGRAFIA E ESTATíSTICA (IBGE). PNAD Contínua 2016: $10 \%$ da população com maiores rendimentos concentra quase metade da renda. 2017. Disponível em: http://bit.ly/2FmPhLL. Acesso em: 23 out. 2018.

INSTITUTO RECIVITAS. Renda básica de cidadania: afinal o que é renda básica? [2019]. Disponível em: https://www.recivitas.org/o-que-e-renda-basica. Acesso em: 1ㅇs. 2018.

LAKATOS, E. M.; MARCONI, M. de A. Fundamento de metodologia científica. 4. ed. rev. e ampl. São Paulo: Atlas, 2001. 
OPIELKA, M. The feasibility of a basic income. The Foundation for Law Justice and Society. Oxford: Universityof Oxford, 2008.

POCHMANN, M. Desenvolvimento, trabalho e solidariedade: novos caminhos para a inclusão social. São Paulo: Cortez, 2002.

SUPERIOR TRIBUNAL FEDERAL (STF). Arguição de Descumprimento de Preceito Fundamental ADPF 132. Relator Ministro Ayres Britto, Tribunal Pleno. Julgamento: 5 maio 2011.

SUPERIOR TRIBUNAL FEDERAL (STF). Recurso Extraordinário. Relator Mininstro Luiz Fux, Tribunal Pleno. Julgamento. 9 fev. 2017.

SUPLICY, E. M; CURY, S. A renda mínima garantida como proposta para remover a pobreza no Brasil. Revista de Economia Política, São Paulo, v. 14, n. 1, p. 101-119, 1994.

WEBER, T. A ideia de um mínimo existencial de J. Rawls. Kriterion, Belo Horizonte, n. 127, p. 197-210, jun. 2013. 